\title{
解Irestice \\ Ensinando química e bioquímica de alimentos através de revistas em quadrinhos
}

\author{
Teaching food chemistry and biochemistry through comics
}

\author{
Rebeca Novais Brandão1, Renata Lênnen da Cruz e Silva², Ana Carolina Rudes Ferreira ${ }^{3}$, \\ Wanessa Costa Silva Faria ${ }^{4}$
}

\section{Resumo}

Introdução e objetivos: Numa época em que os acadêmicos estão cada vez mais adeptos do uso da realidade virtual, o gênero de quadrinhos com animações e de ficção científica permanecem populares. Método: Neste trabalho, discentes do curso superior de Ciência e Tecnologia de Alimentos da Universidade Federal de Mato Grosso (UFMT) desenvolveram revistas em quadrinhos, utilizando o software on-line Pixton. Nos quadrinhos, foram apresentadas de forma ilustrativa e dinâmica, as funções biológicas, químicas e tecnológicas de pigmentos e vitaminas lipossolúveis. Resultados: $A$ revista em quadrinhos foi distribuída de forma impressa na feira semestral denominada Experimente e disponibilizada on-line na forma de Flip-book, com isso, foi possível chamar a atenção dos discentes, docentes e comunidade, para outros meios de informação e comunicação, tornando o conteúdo de fácil assimilação, devido as ilustrações e fácil vocábulo utilizados pelos discente, o que possibilitou atingir um público maior. Conclusão: Com o uso desse recurso, foi possível melhorar a assimilação do conteúdo, além de aguçar a criatividade dos discentes e interesse pela disciplina de Química e Bioquímica de Alimentos.

Palavras-Chave: Ferramentas de ensino, tecnologias da informação, vitaminas lipossolúveis, pigmentos lipossolúveis.

\footnotetext{
Abstract

Introduction: Nowadays academics are increasingly adept at using virtual reality. Science fiction remains a popular genre for animation and comic books. Method: In this work, students from the College of Food Science and Technology at Federal University of Mato Grosso (UFMT), developed comic books using the online software Pixton. Results: In these comics, the biological, chemical and technological functions of both fat-soluble pigments and vitamins were presented in an illustrative and dynamic way. They were printed and distributed during the biannual science fair Experimente. Other than the comics a flip-book was published online. Using this method, the authors were able to draw the attention of the students, teachers and the community, to a new

1. Acadêmica de graduação. Curso de graduação Ciência e Tecnologia de Alimentos da Faculdade de Nutrição da Universidade Federal de Mato Grosso (UFMT). E-mail: rnbran@hotmail.com

2. Acadêmica de graduação. Curso de graduação Ciência e Tecnologia de Alimentos da Faculdade de Nutrição da Universidade Federal de Mato Grosso (UFMT). E-mail: relennen@gmail.com

3. Acadêmica de graduação. Curso de graduação Ciência e Tecnologia de Alimentos da Faculdade de Nutrição da Universidade Federal de Mato Grosso (UFMT). E-mail: caroolrudes@gmail.com

4. Doutora em Ciência de Alimentos. Curso de graduação Ciência e Tecnologia de Alimentos da Faculdade de Nutrição da Universidade Federal de Mato Grosso (UFMT). E-mail: wanessacsf@gmail.com

Correspondência: Av. Fernando Corrêa da Costa, 2367 - Boa Esperança, Cuiabá - MT, 78060-900. Departamento de Alimentos e Nutrição, curso de Ciência e Tecnologia de Alimentos - Bloco B.
} 
medium of information and communication, through the use of an informal and easy-going language which made the content, heavily packed with biochemistry, easier to understand. Conclusion: Indeed, it is possible to say that this initiative allowed for a greater understanding of the subject, with the use of students creativity and increased interest in the discipline of Food Chemistry and Biochemistry also being noteworthy.

Keywords: Teaching tools. Information technology. Fat-soluble vitamins. Fat- soluble pigments.

\section{Introdução}

Com o avanço da tecnologia e o desenvolvimento de novos meios de informação e comunicação surgiram alternativas de aprimoramento e implantação de novas técnicas na área de educação. O advento da revolução da informática trouxe inúmeros impactos que atingiram diversas áreas sociais ${ }^{1}$. A educação é mais um dos setores atingidos por essas mudanças. Cada vez mais a tecnologia se faz necessária no aprendizado discente, seja pelo uso de equipamentos tecnológicos ou por meio de projetos envolvendo educação em tecnologias, uma vez que novas alternativas tecnológicas surgem diariamente e podem auxiliar os professores e estudantes no processo de ensino e aprendizagem ${ }^{1}$.

A principal dificuldade de se incorporar as Tecnologias de Informação e Comunicação (TIC) no processo de ensino, é o fato do professor ainda ser apontado com o detentor de todo o conhecimento. A pedagogia Freireana critica o princípio que parte do pressuposto de que o professor é o ser ativo, detentor do conhecimento e que o aluno é passivo, apenas um receptor de informações. Chiarella et $\mathrm{al}^{2}$, em estudo sobre o papel da pedagogia de Paulo Freire na educação médica, enfatiza que ambos, professores e alunos, são transformados no processo da ação educativa e aprendem ao mesmo tempo em que ensinam

De acordo com Sampaio ${ }^{3}$, para que o uso das TIC signifique uma transformação educacional positiva, os professores terão que redesenhar seu papel e sua responsabilidade como educador. A utilização das TIC nas aulas, implica um suplemento de trabalho para o docente e de tempo para conseguir preparar recursos digitais. No entanto, vale ressaltar que as salas de aulas ainda não estão suficientemente equipadas para trabalhar com os recursos das TIC.

Em muitas aulas de ciências, são relatados carência nas metodologias de ensino, pois a matéria é estritamente racional, baseada, em sua grande maioria, na relação teoria-exercício-teoria, em que o aluno é incentivado a memorizar equações e teorias, que fundamentam a resolução de avaliações e exercícios, alguns sem relação com o seu cotidiano, o 
que gera desinteresse por parte do aluno em saber e fazer ciência. Entretanto, para que haja eficácia no processo de aprendizagem, a inserção de novos recursos didáticos se faz cada vez mais necessários com o fim de tornar as aulas mais didáticas e interativas ${ }^{2}$. O objetivo dessa interatividade é despertar o interesse científico e a curiosidade a respeito de assuntos científicos por parte dos alunos ${ }^{4}$.

Com isso, há diversos meios de ensinamento que 0 professor pode explorar, assim sendo faz-se necessária a incorporação de inovações tecnológicas em detrimento ao ensino tradicional, com o fim de otimizar o processo de aprendizagem. Mediante as necessidades do ensino de ciências, o professor deve fornecer ao acadêmico oportunidades de adquirir um olhar crítico sobre os conteúdos estudados e uma visão mais equilibrada sobre a natureza do conhecimento científico, favorecendo o seu posicionamento de forma satisfatória diante de situações às quais requeiram o uso de conhecimentos sobre a ciência.

Segundo Koutníková ${ }^{5}$, o apoio ao interesse em tópicos científicos, combina muito bem com a gama de oportunidades para trabalhar com quadrinhos. Os quadrinhos trazem estratégias didáticas não tradicionais para o desenvolvimento da educação científica, que são, no entanto, complicadas em termos de suas demandas sobre o conceito didático de um conteúdo que requer uma abordagem transdisciplinar.

Logo, o processo de criação de uma história em quadrinhos estimula a criatividade do aluno e o olhar crítico acerca do assunto, ou seja, o fato de se incentivar acadêmicos do ensino superior a criar histórias em quadrinhos, além de ser um método muito pouco explorado, possui potencialidade pedagógica e pode oferecer suporte a outras estratégias didáticas.

De acordo com Presser e Braviano ${ }^{6}$, a introdução de cenas cômicas nos currículos acadêmicos como um meio para o ensino ofereceu uma experiência de aprendizado divertida e amigável, e apresenta um potencial maior de envolvimento caso seja trabalhado de maneira diferenciada. lanesco ${ }^{7}$ mensurou a eficiência no processo de ensinoaprendizagem no ensino em ciências em turmas do ensino médio, os resultados obtidos pelos autores sugerem que a elaboração de histórias em quadrinhos é uma ferramenta eficiente na assimilação de assuntos científicos.

A inserção de quadrinhos abordando temas relacionados à química e bioquímica de alimentos em universidades são escassos. Neste contexto, o objetivo deste artigo foi de apresentar o projeto desenvolvido no decorrer do semestre letivo da matéria de Química e Bioquímica de Alimentos, no curso de Ciência e Tecnologia de Alimentos da Faculdade de 
Nutrição da Universidade Federal de Mato Grosso - Campus Cuiabá.

\section{Métodos}

Para o desenvolvimento da revista em quadrinhos, acadêmicos matriculados na disciplina de Química e Bioquímica de Alimentos, ministrada no Curso de Ciência e Tecnologia de Alimentos da Faculdade de Nutrição da Universidade Federal de Mato Grosso, utilizaram como ferramenta o software on-line pixton ${ }^{8}$.

A turma foi dividida em duplas ou trios, em que cada um recebeu um tema para a produção dos quadrinhos, sendo estes: Papel da vitamina A no organismo; carotenoides como fonte de provitamina $A$; papel da vitamina D no organismo, a vitamina $E$ e seu uso na indústria alimentícia como aditivo antioxidante; vitamina $\mathrm{K}$ e suas funções no organismo; e, por último, pigmentos lipofílicos de origem natural e suas aplicações na indústria de alimentos.

O número de quadrinhos/páginas ficou a critério dos alunos, no qual o gibi conta com em média 19,16 quadrinhos por tema e o gibi tem 22 páginas ao total (FIGURA 1). Após o prazo de produção das histórias as mesmas foram submetidas a correção da docente em que foram indicados os erros e reparos a serem feitos pelos os alunos para a finalização do projeto.

Com as histórias em quadrinhos concluídas a mesma foi disponibilizada como forma de mídia virtual em forma de flip-book e impressa, sendo estas apresentadas na feira semestral Experimente, na qual são apresentados trabalhos desenvolvidos no curso de Ciência e Tecnologia de Alimentos. Cada grupo expôs oralmente o processo de produção das histórias e desenvolveu a explicação de cada tema abordado na revista.

\section{Figura 1 nos anexos}

\section{Resultados}

Nas histórias desenvolvidas pelos estudantes, houve variedades de cenários, personagens e narrativas, não sendo nenhum capítulo parecido com o outro. No primeiro capítulo o tema tratado foi "O Papel da vitamina A no organismo", o cenário usado é de dois amigos que começam a conversar sobre como a falta dela a afeta a homeostasia e de como é possível adquiri-la através da alimentação. Logo em seguida, o tema abordado foi "A vitamina $E$ e seu uso na indústria alimentícia como aditivo antioxidante", o enredo criado pelos autores envolve uma entrevista com dois Cientistas de Alimentos em um programa de plateia, no qual ambos destrincham a ação desta vitamina como aditivo alimentar. $\mathrm{Na}$ história sobre pigmentos lipofílicos de origem natural, a personagem Kamila, estudante de graduação Ciência e 
Tecnologia de Alimentos, explana sobre as principais fontes destes pigmentos e seus pontos positivos e negativos frente aos corantes de origem sintética. O tema sobre - Papel da Vitamina D no organismo é narrado com muita simpatia pelo Sunny (figura 2), este personagem narra a história do personagem chamado Marcelo, que sentiu no corpo como a falta de vitamina $D$ afeta o organismo. Além dessas histórias abordando o papel da vitamina $\mathrm{K}$ no organismo foram desenvolvidas, a função antioxidante e pigmentante de carotenoides, entre outras.

A criação da revista em quadrinhos estimulou a criatividade e melhor entendimento do conteúdo "vitaminas e pigmentos lipossolúveis" dos acadêmicos matriculados na referida disciplina.

O desafio de criar histórias em quadrinhos sobre vitaminas e pigmentos lipossolúveis, resultou em maior interesse acerca dos assuntos por parte dos alunos, os temas dados foram bastante aproveitados nas histórias, resultando num material bastante informativo e com uma linguagem dinâmica. Os estudantes foram capazes de absorver conhecimento e repassar as informações adquiridas, através da pesquisa realizada, à comunidade acadêmica e não acadêmica, visitantes do evento semestral Experimente.

Isso mostra que quando o aluno é instigado a utilizar métodos envolvendo as TIC, há um maior interesse em pesquisar, absorver conhecimento e apresentar de forma simples e didática o que foi aprendido. Com o desenvolvimento das histórias em quadrinhos, os acadêmicos do curso de Ciência e Tecnologia de Alimentos, evidenciaram a capacidade de trabalhar com ferramentas computacionais, tal como softwares online, criar cenários e personagens para as histórias, além disso, desdobrar temas científicos da área de Química e Bioquímica de Alimentos, em enredos com linguagem simples e de fácil entendimento a fim de alcançar, inclusive, indivíduos leigos, para que os conhecimentos/informações acadêmicas desenvolvidas não se limite ao espaço da universidade, mas que a comunidade os conheça e valorize os projetos nela desenvolvidos.

Em estudo de coorte delineado por Burkhart $^{9}$ envolvendo acadêmicos de nutrição que foram avaliados quanto ao engajamento ao método de ensino conhecido por aprendizado invertido ou Flipped classroom, no qual o acadêmico toma conhecimento da matéria antes de ir para sala de aula, e com o tempo em sala de aula sendo usado para aprofundar o entendimento por meio de discussões com colegas e atividades de solução de problemas facilitadas pelos professores. $\mathrm{O}$ resultado desta pesquisa mostrou que $66,5 \%$ dos acadêmicos se engajaram ao método, e que $55 \%$ dos alunos preferem o método de aprendizado invertido ao invés 
do método tradicional de ensino, pelo fato de ser um método ativo de aprendizado ${ }^{9}$. Frente a esse achado, a inferência de que o acadêmico tem preferência por ser agente ativo no processo de aprendizagem, seja por uso de TIC ou por qualquer outro método de aprendizagem ativo, é verdadeira.

Em artigo de revisão sobre história em quadrinhos como ferramenta de ensino sobre segurança em laboratórios de química, Prado et al $^{10}$ reporta que cenas de quadrinhos podem ser usadas como um meio para facilitar e promover a educação em saúde através da riqueza de informações trazidas em imagens coloridas e divertidas. Vale ressaltar que para a utilização de histórias em quadrinhos como ferramenta de ensino e de divulgação do conhecimento científico, é necessário que haja um consenso entre $a$ arte $e \quad o$ conhecimento cartesiano em prol de um material que interaja com a realidade ${ }^{11}$. Camargo e Rivelini-Silva ${ }^{12}$ destacam que histórias em quadrinhos são elaboradas por alunos a partir de conceitos previamente desenvolvido em sala. Os autores fizeram um levantamento dos artigos abordando histórias em quadrinhos para o ensino em química, dentre eles estão: tabela periódica, estados da matéria, ácidos e bases, densidade, ligações químicas, radioatividade, funções orgânicas e tópicos de química ambiental. Além do objetivo de desenvolver material didático alternativo para ensino de ciências, o desenvolvimento de quadrinhos eleva a percepção dos alunos para além do humor e do entretenimento, uma vez que esses materiais consistem em apenas uma das várias formas de divulgação que influenciam no modo como os alunos concebem essa disciplina, cabendo ao professor orientá-los a distinguir as informações coerentes das equivocadas ${ }^{12}$. Segundo Costa et $\mathrm{al}^{13}$, faz-se necessário a mudança do perfil docente para depois alterar o conhecimento e discernimento dos discentes. A forma de ensinar e propor outros meios de aprendizagem parte do docente responsável. Como podemos ver, métodos alternativos de ensino que exploram as TIC, aguça o interesse do acadêmico no aprendizado de Química e Bioquímica de Alimentos, além disso, gera um ressignificado no ensino face às demandas atuais dos estudantes que vivem em sistemas colaborativos interligados de comunicação e se mostram cada vez mais saturados do discurso linear ${ }^{13}$. Os quadrinhos, como arte sequencial, revelam-se como um método potencial de assimilação e transmissão de conhecimento, tanto na parte ilustrativa quanto na leitura simplificada e dinâmica. Contudo, ainda há uma necessidade de estudos que se proponham a analisar como materiais similares já existentes afetam 0 processo de ensinoaprendizagem. 
Figura 2 nos anexos.

\section{Conclusão}

O conteúdo de química e bioquímica de alimentos, mais especificamente o tema "Vitaminas e Pigmentos Lipossolúveis", pode ser mais bem assimilado por meio do desenvolvimento de histórias em quadrinhos, visto que, além da criação da história, os acadêmicos desenvolveram os personagens e cenários dos quadrinhos. Isso fez com que os discentes aprofundassem ainda mais os conhecimentos sobre o assunto, pois na etapa sequencial ao desenvolvimento, os discentes tiveram que apresentar 0 conteúdo da revistinha para a comunidade acadêmica e não acadêmica, visitantes da feira Experimente.

Ao realizar esse trabalho, foi possível reconhecer as histórias em quadrinhos como ferramenta de divulgação científica em ambientes formais e não formais de ensino, possibilitando o surgimento de novas estratégias no que diz respeito ao ensino de ciências.

Neste aspecto, a criação de histórias em quadrinhos já faz parte da metodologia de ensino na disciplina de Química e Bioquímica de Alimentos no curso de Ciência e Tecnologia de Alimentos da Universidade Federal de Mato Grosso, buscando a cada semestre letivo, abordar novos temas relacionados a disciplina. Além disso, cartilhas explicativas em quadrinhos sobre temas relacionados a
Ciência e Tecnologia de Alimentos, estão sendo desenvolvidas para distribuição física e online em feiras de divulgação sobre mitos e verdades que permeiam os alimentos industrializados.

\section{Agradecimentos}

Agradecemos ao Curso de Ciência e Tecnologia de Alimentos do Departamento de Alimentos e Nutrição da Universidade Federal de Mato Grosso (UFMT) pelo apoio estrutural e impressão das revistas em quadrinho

- Conflito de interesse: Os autores declaram que esta publicação é desprovida de qualquer conflito de interesse ou interesse pessoal/comercial.

\section{Referências}

1. Oliveira C. Tic's na educação: A utilização das tecnologias da informação e comunicação na aprendizagem do aluno.

Periodicos.pucminas.br. 2019 [cited 6 October 2019]. Available from: http://periodicos.pucminas.br/index.ph $\mathrm{p} /$ pedagogiacao /article / view/11019. 2. Chiarella T, Bivanco-Lima D, Moura JC, Marques MCC, Marsiglia RMG. A Pedagogia de Paulo Freire e o Processo Ensino-Aprendizagem na Educação Médica. RevBrasEducMed 2015; 39(3):418-

425.https://dx.doi.org/1 0.1590/1981$52712015 v 39 n 3 e 0206014$.

3. Sampaio PASR. Conhecimento tecnológico dos professores de Matemática sobre quadros interativos segundo as políticas públicas de formação contínua. Ensaio: aval 
polpúblEduc 2016; 24(93): 845 - 865. http://dx.doi.org/10. 1590/S010440362016000400004.

4. Gomes F, Machado SF, Costa LLD, Alves, BHP. Atividades Didático Pedagógicas para o Ensino de Química Desenvolvidas pelo Projeto PIBID-IFG. Quim Nova Escol 2014; 36(3): 211 - 219. http://dx.doi.org /10.5935/01048899.20140024.

5. Koutníková M. The Application of Comics in Science Education. Acta EducationisGeneralis 2017; 7(3): 88 98.

6. Presser A, Braviano G. Uso de Histórias em Quadrinhos digitais como elemento de apoio ao processo de ensino-aprendizagem na educação superior. Congresso Nacional de Ambientes Hipermídia para Aprendizagens 2015, 1 - 11.

7. lanesco F, Andrade CK, Felsner ML, Zatta L. Elaboração e aplicação de histórias em quadrinhos no ensino de ciência. Exp. Ens. Cienc 2012; 12(5): 105 - 123. Disponível em: < if.ufmt.br > eenci > artigos > Artigo ID382 > v12 n5 a2017v > Acesso em 09 de out. 2019.

8. Software Online Pixton. Disponível em <https://www.pixton.com/br/> Acesso em 09 de out. 2019

9. Burkhart SJ, Taylor JA, Kynn M, Craven D. L, Swanepoel L C.

Undergraduate Students Experience of Nutrition Education Using the Flipped Classroom Approach: A Descriptive Cohort Study. J NutrEducBehav2019; $1-7$. https://doi.org/10.1016/j.jneb.2019.06.0 02.

10. Prado CC, Souza Junior CE, Pires

ML. Histórias em quadrinhos: uma ferramenta para a educação e promoção da saúde. Reciis - Ver Eletron Comum Inf Inov Saúde 2017; 11(2): 1 - 12. doi: http://dx.doi.org/10.29397/reciis.v11i2. $\underline{1238}$

11. Silva BVC, Ataide MCES,

Venceslau TKOS. Tirinhas em sala de aula: o que sabem os futuros professores de física? HOLOS2015; 3 : 204-211, doi:https://doi.Org/10.15628/holos.20 15.832 .

12. Camargo SC, Rivelini-Silva AC. Histórias em quadrinhos no ensino de ciências: um olhar sobre o que foi produzido nos últimos doze anos no ENEQ e ENPEC. ACTIO: 2017; 2(3): $133-150$.

13. Costa FC, Souza IT, Cusin CA.O uso das tecnologias da informação no ensino superior.Revista Científica Multidisciplinar Núcleo do Conhecimento 2019; 10(03): 05-28. 2019. Disponível em: <https://www.nucleodoconhecimento.c om.br/tecnologia/informacao-noensino> Acesso em 09 de out. de 2019 
Anexos

Figura 1: Capa das histórias em quadrinhos

\section{PIGMENTOS E VITAMINAS LIPOFÍLICAS por}

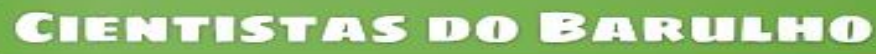

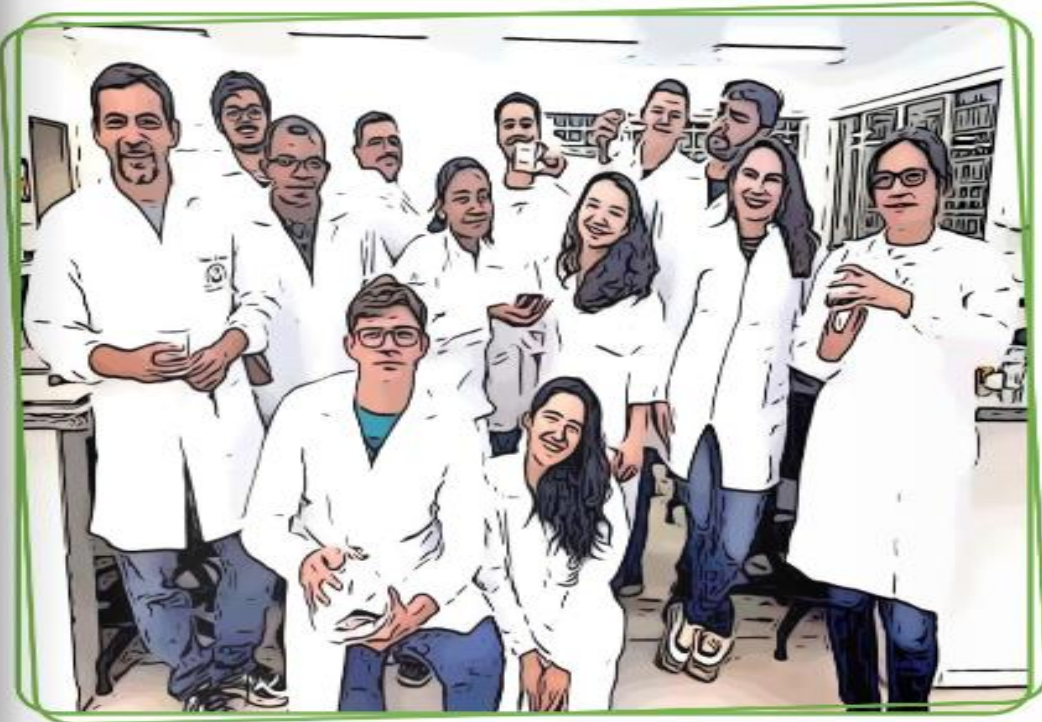

Acadêmicos da disciplina de Composição de Alimentos Curso de Ciência e Tecnologia de Alimentos da UFMT $2019 / 1$

Fonte:Imagem retirada do flip-book (https://www.flipsnack.com/6DF96B7F8D/pigmentos-e-vitaminaslipof-licas.html) 
Figura 2: Quadrinhos sobre Vitamina D, E e K
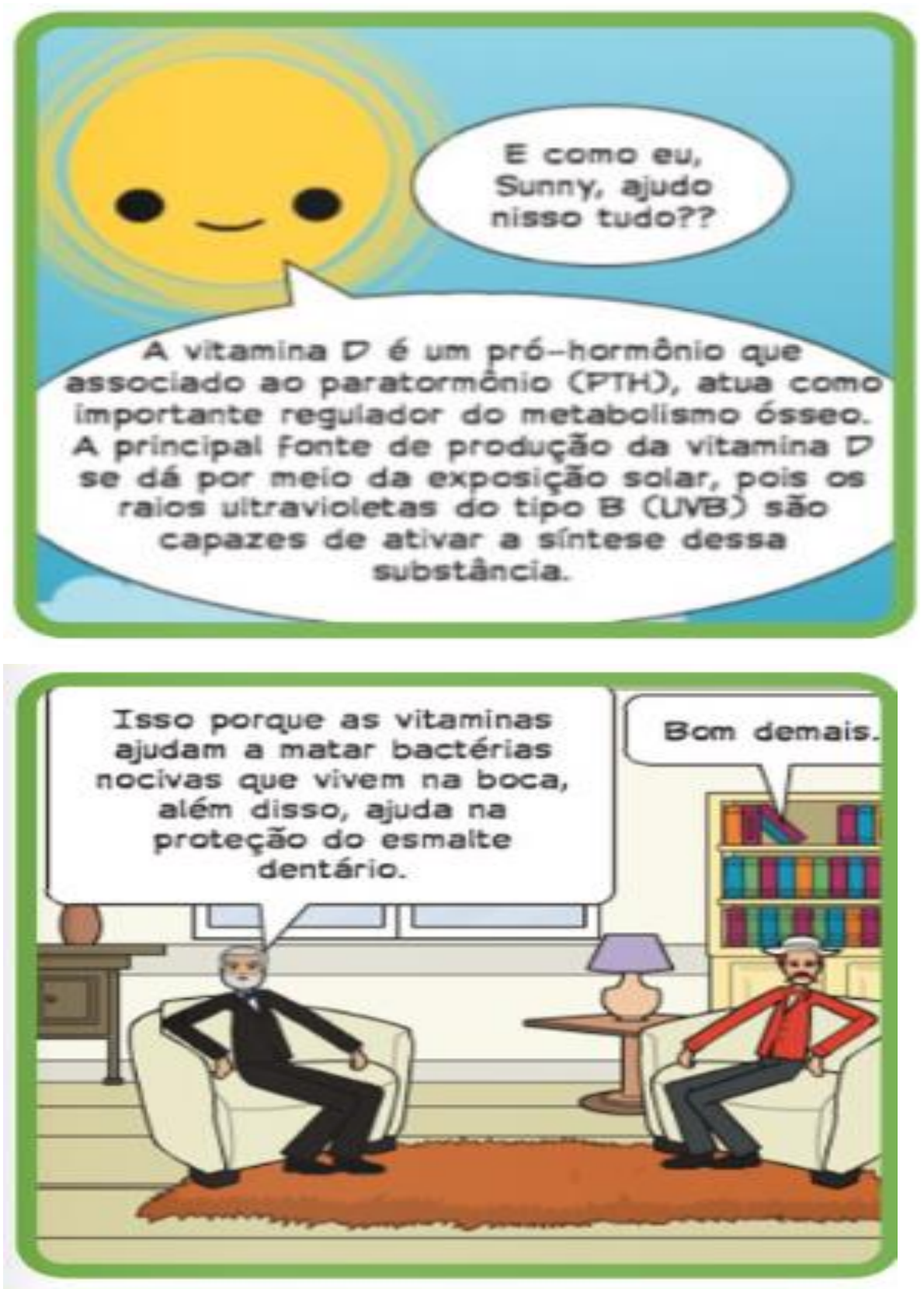

RE. SAÚD. DIGI. TEC. EDU., Fortaleza, CE, v.4, n.2, p.01-12, ago./dez. 2019. ISSN: 2525-9563 
Vocês sabiam que a vitamina $E$ é uma vitamina essencial para - funcionamento do organismo, pois tem potente açăo antioxidante.

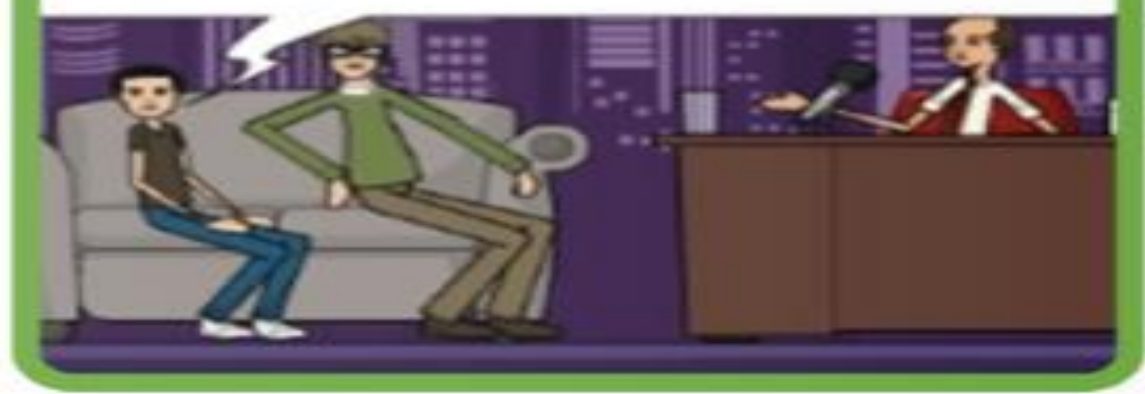

Fonte: Imagem retirada do flip-book (https://www.flipsnack.com/6DF96B7F8D6/pigmentos-e-vitaminaslipof-licas.html) 


\section{Como citar este artigo}

Brandão RN; Silva RLC; Ferreira ACR; Faria WCS. Ensinando química e bioquímica de alimentos através de revistas em quadrinhos. Revista de Saúde Digital e Tecnologias Educacionais. [online], volume 4, n. 2. Editor responsável: Luiz Roberto de Oliveira. Fortaleza, mês e ano, p.0112. Disponível em: http://periodicos.ufc.br/resdite/index. Acesso em "dia/mês/ano".

Data de recebimento do artigo: 09/10/2019

Data de aprovação do artigo: 20/11/2019

RE. SAÚD. DIGI. TEC. EDU., Fortaleza, CE, v.4, n.2, p.01-12, ago./dez. 2019. ISSN: 2525-9563 